\title{
BMJ Open Why women die after reaching the hospital: a qualitative critical incident analysis of the 'third delay' in postconflict northern Uganda
}

\author{
Gasthony Alobo (D) , ${ }^{1,2}$ Emmanuel Ochola, ${ }^{3,4}$ Pontius Bayo, ${ }^{5}$ Alex Muhereza, ${ }^{6}$ \\ Violah Nahurira, ${ }^{7}$ Josaphat Byamugisha (1) 8,9
}

To cite: Alobo G, Ochola E, Bayo P, et al. Why women die after reaching the hospital: a qualitative critical incident analysis of the 'third delay' in postconflict northern Uganda. BMJ Open 2021;11:e042909. doi:10.1136/ bmjopen-2020-042909

- Prepublication history and additional materials for this paper is available online. To view these files, please visit the journal online (http://dx.doi. org/10.1136/bmjopen-2020042909).

Received 18 July 2020 Revised 18 February 2021 Accepted 25 February 2021

Check for updates

(C) Author(s) (or their employer(s)) 2021. Re-use permitted under CC BY-NC. No commercial re-use. See rights and permissions. Published by BMJ.

For numbered affiliations see end of article.

Correspondence to Dr Gasthony Alobo; gasthonya@gmail.com

\section{ABSTRACT}

Objectives To critically explore and describe the pathways that women who require emergency obstetrics and newborn care (EmONC) go through and to understand the delays in accessing EmONC after reaching a health facility in a conflict-affected setting.

Design This was a qualitative study with two units of analysis: (1) critical incident technique (CIT) and (2) key informant interviews with health workers, patients and attendants.

Setting Thirteen primary healthcare centres, one general private-not-for-profit hospital, one regional referral hospital and one teaching hospital in northern Uganda.

Participants Forty-nine purposively selected health workers, patients and attendants participated in key informant interviews. CIT mapped the pathways for maternal deaths and near-misses selected based on critical case purposive sampling.

Results After reaching the health facility, a pregnant woman goes through a complex pathway that leads to delays in receiving EmONC. Five reasons were identified for these delays: shortage of medicines and supplies, lack of blood and functionality of operating theatres, gaps in staff coverage, gaps in staff skills, and delays in the interfacility referral system. Shortage of medicines and supplies was central in most of the pathways, characterised by three patterns: delay to treat, backand-forth movements to buy medicines or supplies, and multiple referrals across facilities. Some women also bypassed facilities they deemed to be non-functional. Conclusion Our findings show that the pathway to EmONC is precarious and takes too long even after making early contact with the health facility. Improvement of skills, better management of the meagre human resource and availing essential medical supplies in health facilities may help to reduce the gaps in a facility's emergency readiness and thus improve maternal and neonatal outcomes.

\section{BACKGROUND}

Globally, maternal mortality is still unacceptably high. By 2017, about 295000 women were still dying every year. ${ }^{1}$ More than half of the global maternal mortality occurs in Sub-Sahara Africa and about a third in South
Strengths and limitations of this study

- This qualitative study used two methods of data collection for diagrammatic and thematic analyses: critical incident technique (CIT) and key informant interview, which are complementary and yield richer data for realist enquiry.

- CIT comprehensively mapped the pathways typically followed by cases of maternal deaths and maternal near-misses in similar settings based on critical case purposive sampling.

- We conducted all interviews within health facilities, which might have influenced some responses.

- Part of this study focused on the referral system; however, the addition of two tertiary facilities in Lira without additional stepdown health centres might limit data saturation and not fully present the primary healthcare centre experience.

- Critical case sampling could be biased by researchers' selection interests; however, the researchers used independent maternal and perinatal death surveillance and response teams at the tertiary hospitals to identify cases based on the principles of analytical generalisation.

Asia. ${ }^{12}$ These regions include fragile, humanitarian and postconflict areas. ${ }^{3}$

In Uganda, maternal mortality ratio declined modestly between 2011 and 2016 from 438 to 336 , but with regional differences due to variations in social determinants of health. ${ }^{4}$ For example, northern Uganda is a postconflict area and is currently host to refugees from South Sudan; these circumstances have exacerbated food insecurity and constrained health resources, with possible suboptimal maternal healthcare in the region. ${ }^{67}$ The leading causes of maternal death (MD) are direct obstetric causes and include haemorrhage, infection, hypertensive disorders, uterine rupture and abortion complications. ${ }^{8} 9$ Malaria and HIV/AIDS 
contribute significantly to the indirect causes of MDs in Uganda. ${ }^{10}$

Several delays also exist along the pathway to care. The 'three delays' model has been widely used to understand the factors that underlie MDs. ${ }^{11}$ The first delay is delay in deciding to seek clinical care during an obstetric emergency, the second delay is delay in reaching the health facility, and the third delay is delay in receiving appropriate care while at the health facility. Compared with the first and second delays, the third delay has been underdocumented and under-researched, with only a few indepth and critical analyses of the pathways followed by women with obstetric complications. ${ }^{12}{ }^{13}$ Moreover, the met need for emergency obstetrics and newborn care (EmONC) in some postconflict regions, and in low-income and middleincome countries (LMICs) generally, is still very low. ${ }^{14-17}$ In the context of Uganda, a low-income country which is conflict-affected and with fragile health and referral systems, it is possible to hypothesise significant delays in receiving EmONC even after arriving at a health facility. Such delays could lead to poor maternal and newborn outcomes. Therefore, the purposes of this study were to (1) explore and describe the pathways that women who require $\mathrm{EmONC}$ go through after deciding to seek care and (2) understand the delays in accessing EmONC after reaching a health facility.

\section{METHODS \\ Study design}

This qualitative study used an embedded study design with two units of analysis: (1) critical incident analysis of maternal deaths (MD) and maternal near-misses (MNM) and (2) key informant interviews (KII) with persons who were perceived to know about maternal healthcare by their roles as health workers or experience with the health system. The critical incident technique (CIT) was first described by Flanagan ${ }^{18}$ in 1954 as a way of collecting specific and significant behavioural facts, thus giving a solid basis for making inferences. It has been used as a qualitative methodology in health systems research and is useful in exploring barriers to quality care or to achieving satisfaction with care provision. ${ }^{19}$ It involves the analysis of specific incidents to determine what actions or behaviours could 'lead to the best possible outcome of a given situation'. ${ }^{20}$ The use of CIT complements KII by drawing on more specific experiences and thereby eliciting richer data for realist enquiry. ${ }^{21}$

\section{Study setting and population}

Northern Uganda has an estimated population of 7.1 million and a total fertility rate of 5.4 children per woman. ${ }^{5}$ The first part of this study was carried out in northern Uganda to explore the pathway to care of mothers accessing EmONC services through the referral system to Lacor Hospital. The hospital is located in Gulu District in the postconflict Acholi subregion, west of northern Uganda. It provides comprehensive EmONC
(CEmONC) services and also serves as a referral site for the greater northern Uganda. It has three satellite level 3 health centres $(\mathrm{H} / \mathrm{C})$ within an average distance of 70 km, Pabbo, Opit and Amuru, which offer basic EmONC (BEmONC) services. The main means of transport is motorcycle due to poor road networks. The second part of the study was carried out at Lira Regional Referral Hospital and Lira University Teaching Hospital in the Lango subregion, east of northern Uganda. The addition of these two tertiary facilities aimed to increase the number of participants to achieve saturation. The population used in CIT and KII included patients' relatives and attendants, facility-based key informants, and the patients themselves for MNM.

\section{Sampling and participants}

Key informants

We used a purposive sampling technique to identify and recruit the first few key informants, who were healthcare workers as well as unit in-charges and attendants with knowledge of critical incidents or members of the maternal and perinatal death surveillance and response (MPDSR) teams at Lacor Hospital, Lira Regional Referral Hospital and Lira University Teaching Hospital. This was followed by a snowball technique to identify further key informants, including ambulance drivers, midwives, patients and relatives who also participated in care during critical incidents. During data collection, we also identified other key informants in the above categories who agreed to participate in this study. A total of 49 key informants took part in this study (table 1).

\section{Critical incidents}

We used critical case purposive sampling to identify cases. We restricted ourselves to MD and MNM as critical incidents. Critical case sampling has been described as 'a method where selected important or critical cases are examined based on the following: 'If it happens there, will it happen anywhere?' or 'if that group is having problems, then can we be sure all the groups are having problems?"22 The MPDSR teams of the hospitals identified a total of 50 cases that had complete records and met the criteria for critical case purposive sampling. To enhance the transferability of the findings, we only included 8 MDs and 15 MNMs that went through the referral system in more than two facilities, except for the Lango subregion.

\begin{tabular}{|c|c|c|c|}
\hline Category & $\begin{array}{l}\text { Acholi } \\
\text { subregion }\end{array}$ & $\begin{array}{l}\text { Lango } \\
\text { subregion }\end{array}$ & Total \\
\hline Doctors & 3 & 2 & 5 \\
\hline Midwives & 6 & 3 & 9 \\
\hline Ambulance drivers & 2 & 1 & 3 \\
\hline Patients & 9 & 6 & 15 \\
\hline Attendants & 11 & 6 & 17 \\
\hline
\end{tabular}




\section{Data collection}

We conducted interviews after an initial process of informed consent from all participants, which was verbal because the study presented no more than minimal risk or harm, and in the case of family members to minimise the intrusiveness of the process at a time of grieving. The interviews and mapping of the pathways were conducted from November 2017 to December 2019 in the Acholi subregion. Additional mapping of pathways for cases and interviews at the two tertiary hospitals in the Lango subregion were done in June 2020. The interviews were scheduled at a time agreed on with each interviewee, and all took place at the hospitals and within 2 weeks of the occurrence of MD and MNM to avoid potential loss to follow-up and recall bias. For CIT, each interview began with self-introduction since some participants were not known to the interviewers, followed by collection of demographic and family background information. In all cases, semistructured interviews were carried out in Luo for the patients and their relatives or attendants and in English for the health workers. For each case, we conducted group or individual interviews, as chosen by the participants. The former case involved one respondent narrating the entire series of events surrounding a critical incident, followed by a further enquiry or additional contribution from the members. The following were the four guiding questions: 'when did (name of the woman) start having labour pains or feeling unwell?' 'where did she go to?' 'how did she reach there and how long did she take?' 'what happened on arrival at the facility?' However, the interviewers allowed participants to express themselves freely, audio-recorded, or took systematic notes (with verbal permission of the respondent), and where possible sketched a diagrammatic pathway for each case. Additional questions were also asked regarding antenatal care attendance and risk factors. For the facility in-charges, we asked questions related to quality and accessibility of EmONC services in northern Uganda. Before concluding each interview, the interviewers revisited the diagrammatic pathways to clarify any remaining uncertainties or gaps and member checking where necessary. All the interviews were concluded by asking the interviewees for recommendations to improve EmONC services, with a focus on reducing the third delay, then thanking the participants (online supplemental file).

\section{Data analysis}

All interviews were transcribed and translated to English. The transcripts were read through several times to identify the major themes and become familiar with the content. The pathways to care were mapped for each case from onset of labour pain or danger signs to discharge, whether alive or dead, with a major focus on the time while at the health facility. This mapping helped to identify key events such as decisions and decision-makers, transport means, points of referrals, timeframes and geographical locations of these critical cases. A critical incident report that merged data from CIT and KII was then developed, followed by mapping of the pathway for each case. To add to its rigour, this pathway analysis was also looked at by other members of the team. We completed the mapping of the incidents by hand and Excel Shapes once the team members agreed on its accuracy. A thematic inductive analysis was used for KII. We followed the six steps of thematic analysis: familiarisation, coding, generating themes, reviewing themes, defining and naming themes, and writing up. ${ }^{23}$ NVivo V.10 software was used to manage the data.

\section{Patient and public involvement}

The concept and design of this research were informed by experiences shared by patients and care-takers during routine care for childbirth. We have shared the results, especially critical incidents, with the district and national stakeholders.

\section{Ethical consideration}

This study was approved by the Lacor Hospital Institutional Research Ethics Committee (LHIREC) and the Uganda National Council for Science and Technology, within the Mother and Child Health Lacor and South Sudan. We obtained approval to get verbal consent from all the participants since the study had no more than minimal risk or harm. The interviewers took into consideration the sensitive issues that surround deaths in most cultures of northern Uganda. Whenever the interviewees showed any sign of emotional distress, the interviews were adjourned.

\section{RESULTS}

After analysing the pathways from the CIT and data from the KII, we found that a pregnant woman goes through a complex pathway that leads to delays in receiving care while at the health facility, sometimes with suboptimal outcomes. Underlying these delays were shortage of medicines and supplies, lack of blood, gaps in staff coverage and skills in managing obstetric emergencies, and barriers in the referral system, as summarised in figure 1. The CIT elucidated similar pathways of maternal mortality in all the selected cases: delay to treat, back-and-forth movements to buy medicines or supplies, and referral across multiple facilities that were deemed non-functional. Some women bypassed facilities they perceived to be non-functional or sought care from traditional birth attendants (TBAs) and religious leaders.

\section{Shortage of medicines and supplies}

A midwife reported that patients sometimes buy emergency medicines such as oxytocin and magnesium sulfate as they wait for the next delivery of medicines and supplies from the national medical store. Some key informants cited severe shortage of supplies such as gloves, fluid giving sets, urinary catheters and intravenous cannulas as one of the reasons for delay in receiving EmONC services. As a result, a lot of time is wasted trying to raise money to buy these supplies. 


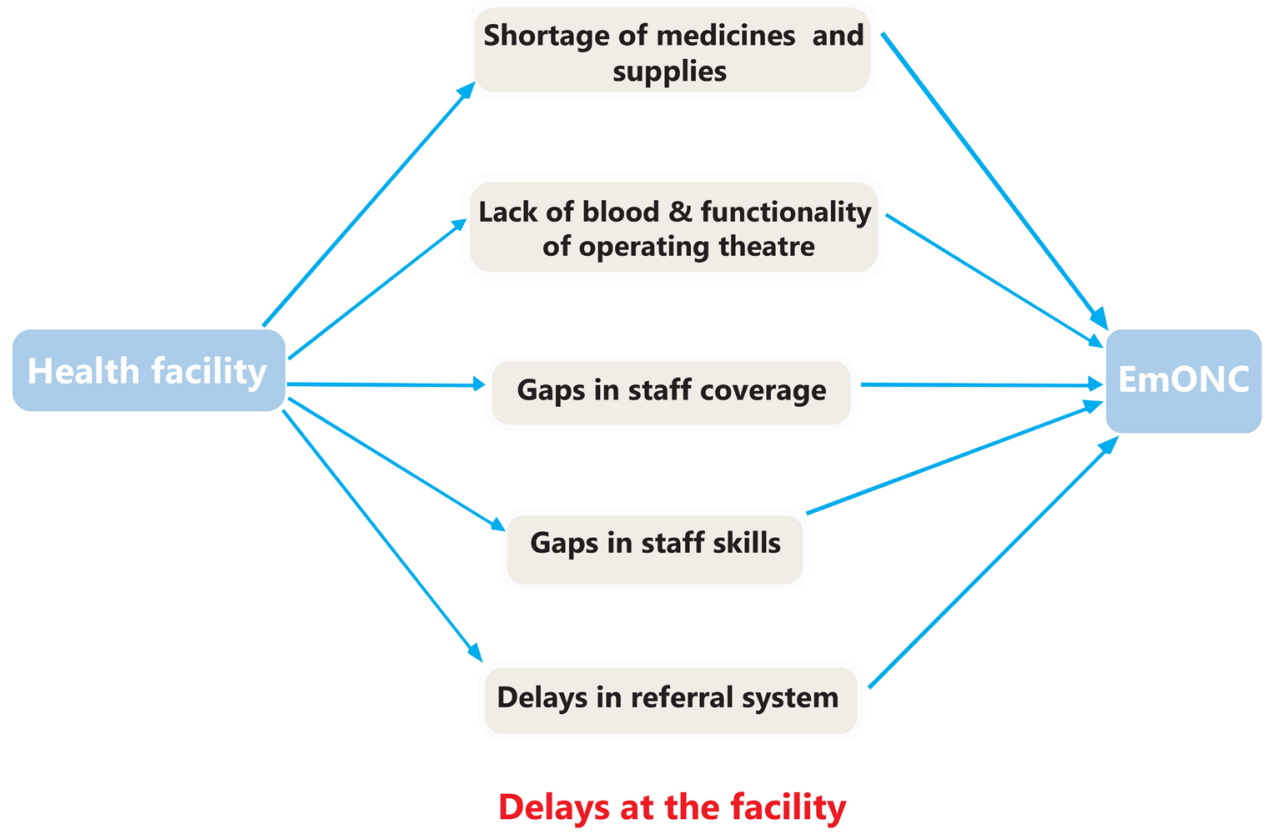

Figure 1 Barriers along the pathway to receive care after reaching the health facility. EmONC, emergency obstetrics and newborn care.

She was in labour for two days at the health centre. When we reached the regional referral hospital, they told us to buy gloves and a tube for urine. The husband ran home to borrow money. When he came back the doctor told us that the womb had ruptured and that we use that money to go to Lacor Hospital. It's bad, she died. (Mother-in-law of an MD case, Lacor Hospital)
Lack of antihypertensives and anticonvulsants was a common problem in BEmONC facilities, while CEmONC facilities lack anaesthetic drugs and spinal needles. For example, figure 2 illustrates a delay in receiving emergency medications for hypertensive disorders and bypassing facilities with non-functional operating theatres.

Depending on geographical location, the nearest health facility where a woman in the village could get

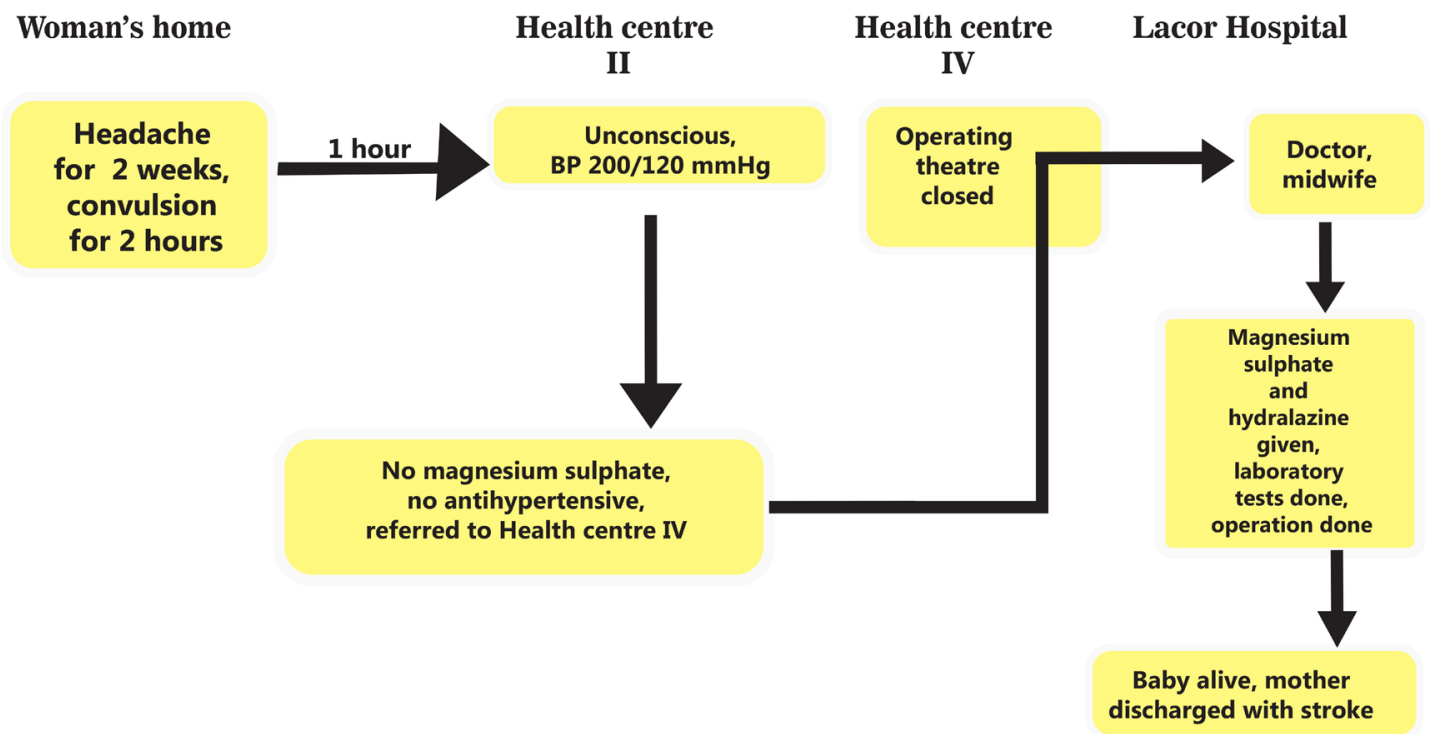

Figure 2 Delayed referral and bypassing non-functional facility. The mother experienced headache for 2 weeks at home before going to $\mathrm{H} / \mathrm{C}$ II, where a diagnosis of severe pre-eclampsia was made. There were no antihypertensives and anticonvulsants. She was referred to nearby H/C IV, but after calling the midwife in charge they were told that the theatre is closed because there were no anaesthetic drugs. They decided to bypass this $\mathrm{H} / \mathrm{C}$ and move to Lacor Hospital, about $90 \mathrm{~km}$ away. At Lacor Hospital, she received anticonvulsants and antihypertensives. She was taken to the operating room for an emergency caesarean section where a live baby was delivered. The mother was discharged alive but had a stroke (MNM1). BP, blood pressure; H/C, health centre; MNM, maternal near-miss. 
EmONC is a primary healthcare centre (PHCC) II or III serviced by a midwife and a clinical officer. However, most of the PHCCs in the region are not fully functional due to frequent stock-outs of EmONC signal function drugs. As a result, the EmONC services are mainly offered by the tertiary level facilities that include the regional referral hospital (RRH) and national referral hospital (NRH).

We are now receiving very many referrals from the lower $\mathrm{H} / \mathrm{Cs}$ due to lack of oxytocin and intravenous fluids. It's now two months since the drugs were delivered to those facilities. (Midwife, Lira RRH).

According to some patients and their relatives, health facilities in urban areas are mainly privately owned and often do not experience stock-outs of medicines, but they are too costly for the poor population. The slum-dwellers, who are largely poor, are served by public RRHs. The typical pathways of MDs and MNMs that we observed for MDs from urban areas are not different from the remote areas, mainly due to lack of tracer medicines and medical supplies.

It's true, sometimes we get bad outcomes of the mother or baby because of drug stock-outs. Remember these are very poor women from the slums. What do you do if a mother can not buy medicines from the private pharmacies in times of stock-out and yet she is actively bleeding? (Midwife, Lira RRH)

\section{Lack of blood and functionality of the operating theatres}

According to Uganda's health system policies, all level 4 $\mathrm{H} / \mathrm{C}$ and hospitals are supposed to offer CEmONC. This requires that they have facilities to perform emergency caesarean sections and blood transfusion. The stakeholders that we interviewed reported that these facilities are not fully functional in some areas. Some health workers and attendants reported blood shortage being worse during holidays since students comprise the largest number of donors. Some patients and attendants reported waiting for blood or being referred to another health facility during times of blood scarcity.

We reached at $8.00 \mathrm{pm}$ but had to wait for 4 hours for blood. There was only one unit from the blood bank, yet they needed four units so that the operation could be done. She was bleeding too much and died on the way here. (Husband of an MD case, Lacor Hospital)

As illustrated in figure 3, lack of blood was noted across all levels of facilities, including Lacor Hospital, and other tertiary hospitals.

By design, all $\mathrm{H} / \mathrm{C}$ IVs have operating theatres but some are not fully functional. Lack of anaesthetists, spinal anaesthesia drugs and needles was cited as reason for the non-functionality of the operating theatres, as illustrated by a case in figure 4 .

We get so many referrals from $\mathrm{H} / \mathrm{C}$ IVs for emergency Caesarean section; of course with bad outcomes quite often. At least for us here patients can buy some drugs from the pharmacies in case of stock-outs, which is not the case in the villages where the $\mathrm{H} / \mathrm{C}$ IVs are. (Midwife, Lira University Teaching Hospital)

\section{Gaps in staff coverage}

Gaps in staff coverage were referred to as a 'chronic' problem across all public health facilities by most

\section{Woman's home Regional Referral Hospital Lacor Hospital}

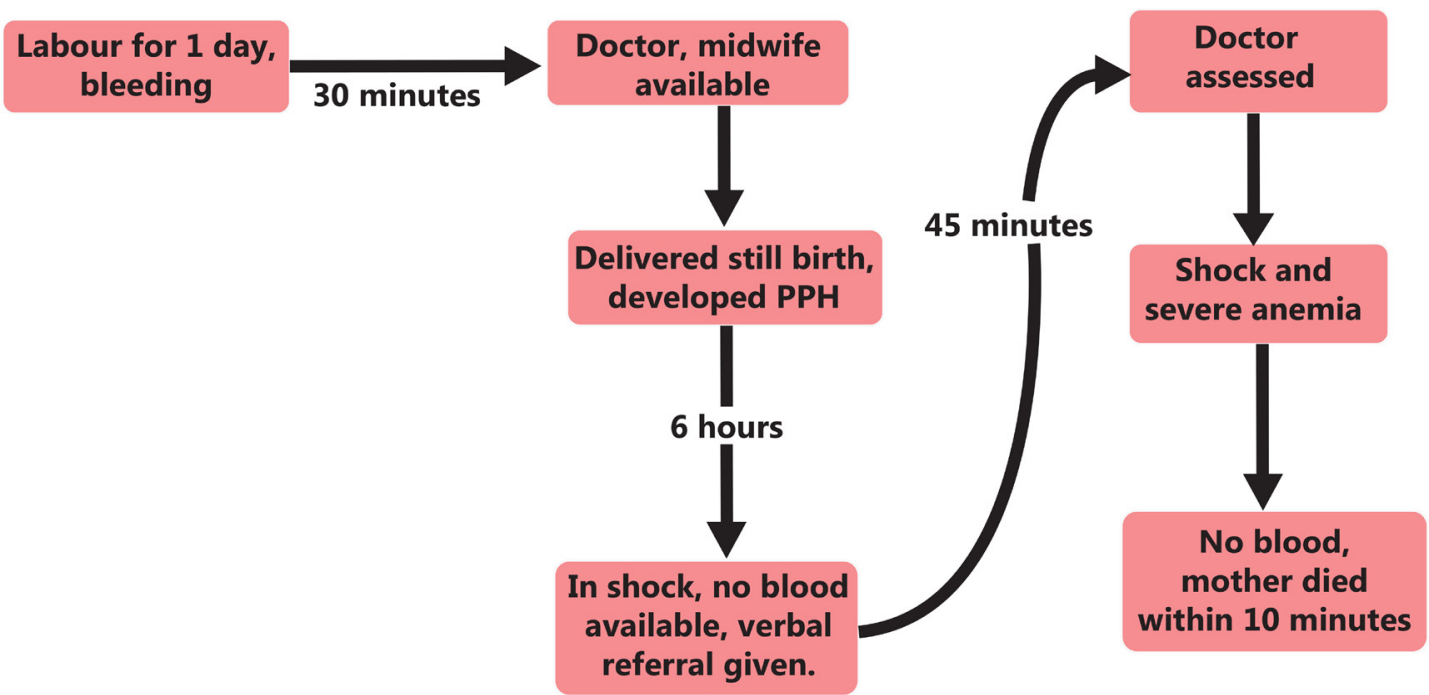

Figure 3 Lack of blood. The mother experienced labour pain for 1 day and bleeding for 4 hours before going to the regional referral hospital. She had fresh stillbirth and developed postpartum haemorrhage. The doctor requested 3 units of blood but there was no available blood. She was referred to Lacor Hospital with severe anaemia. At Lacor Hospital there was no available blood as well. She died at the admission point (MD1). MD, maternal death; PPH, post partum haemorrhage. 


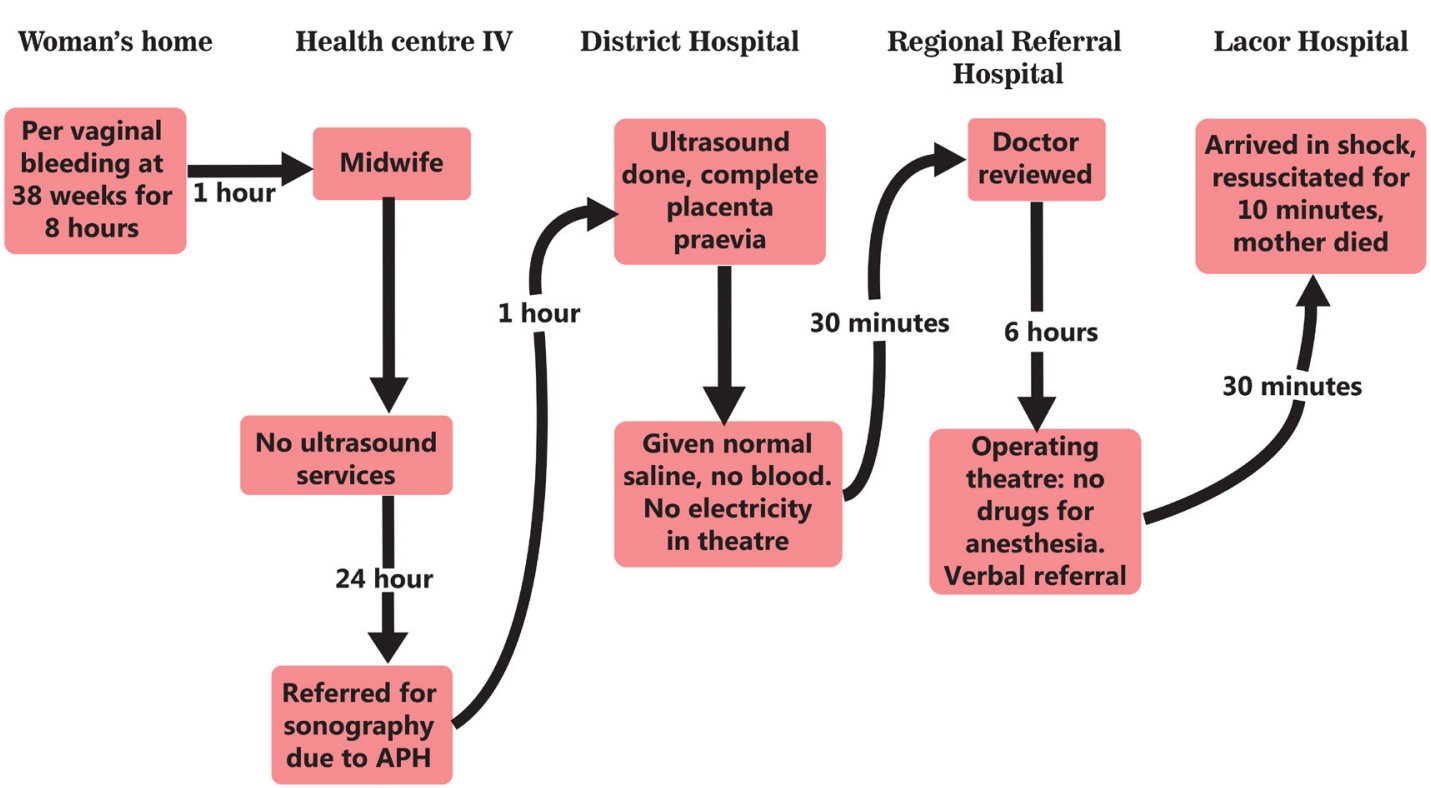

Figure 4 Multiple referrals across non-functional CEmONC facilities. The mother had APH and went to H/C IV, but the midwife referred her to the district hospital for an ultrasound scan; it confirmed complete placenta praevia. A decision to do an emergency caesarean section was made but the operating room did not have electricity, prompting referral to $\mathrm{RRH}$. At $\mathrm{RRH}$ she spent 6 hours looking for money to buy drugs for anaesthesia. After failing to get the money, she was verbally referred to Lacor Hospital but had bled a lot and died of haemorrhagic shock (MD2). APH, antepartum haemorrhage; CEmONC, comprehensive emergency obstetrics and newborn care; $\mathrm{H} / \mathrm{C}$, health centre; MD, maternal death; $\mathrm{RRH}$, regional referral hospital.

non-facility-based key informants. For most of the lower $\mathrm{H} / \mathrm{Cs}$, the key informants reported that the only available midwife in each facility is often away for training and workshops, leaving only nursing assistants who largely lack midwifery training. In most CEmONC facilities, the doctors and anaesthetists are sometimes not available on weekends or public holidays. The stakeholders attributed this to lack of supervision by the facility in-charges and the district health officers.

There is no H/C IV that is fully functional. Well, the structures are there but the personnel are not available full time especially on weekends and at night. For example, doctors. It's not easy to find them full time at work. I was told to wait until Monday... Imagine, I would be dead now. (MNM case, Lira RRH)

In the analysis of the pathways, skilled personnel are critical in executing timely interventions to treat or refer. Figure 5 illustrates a delay to treat and refer. Some facilities often close their maternity units when the midwives are not available, making patients seek alternative care from TBAs and religious leaders (figures 6 and 7).

\section{Skills of the staff}

Skilled birth attendants are necessary for early identification and management of obstetric complications as indicated by facility in-charges. Many patients and their attendants reported that midwives take too long to intervene, including referral to a higher facility when needed. Some women reported that they had to demand referrals, but ended up with bad outcomes.
Last week, I laboured for four days at the health facility. I told the midwife that this is not how my labour has always been [...]. She said that I was pretending and that everything was fine because some labours take long like that.... I had a sharp pain then started bleeding seriously, she then told us to go to the main hospital.... my womb was torn already and they removed it. I thank God that I'm still alive. (MNM case, Lacor Hospital)

During the KII, some stakeholders pointed out training gaps among doctors and midwives. As a result, the health workers have knowledge and skill gaps and often take long to intervene, causing unnecessary delays.

... the midwives and doctors of these days are 'half baked.' They are very slow and take long to decide. They can't handle emergencies because you have to act fast. (Midwife, Lacor Hospital)

A critical training gap was reported in some privately owned midwifery schools that lack teaching hospitals. A midwife supervisor also cited a lack of internship for certificate and diploma midwives. Figure 8 illustrates a possible gap in skills where a midwife kept a mother in active labour for 3 days.

\section{Delays in the referral system}

There were reports of interfacility delays due to the unfavourable state of the roads. According to the ambulance drivers, most roads that link the BEmONC facilities to CEmONC facilities are almost impassable, especially during rainy seasons. The roads usually flood when it rains heavily. This leads to a delay during the referral process. 


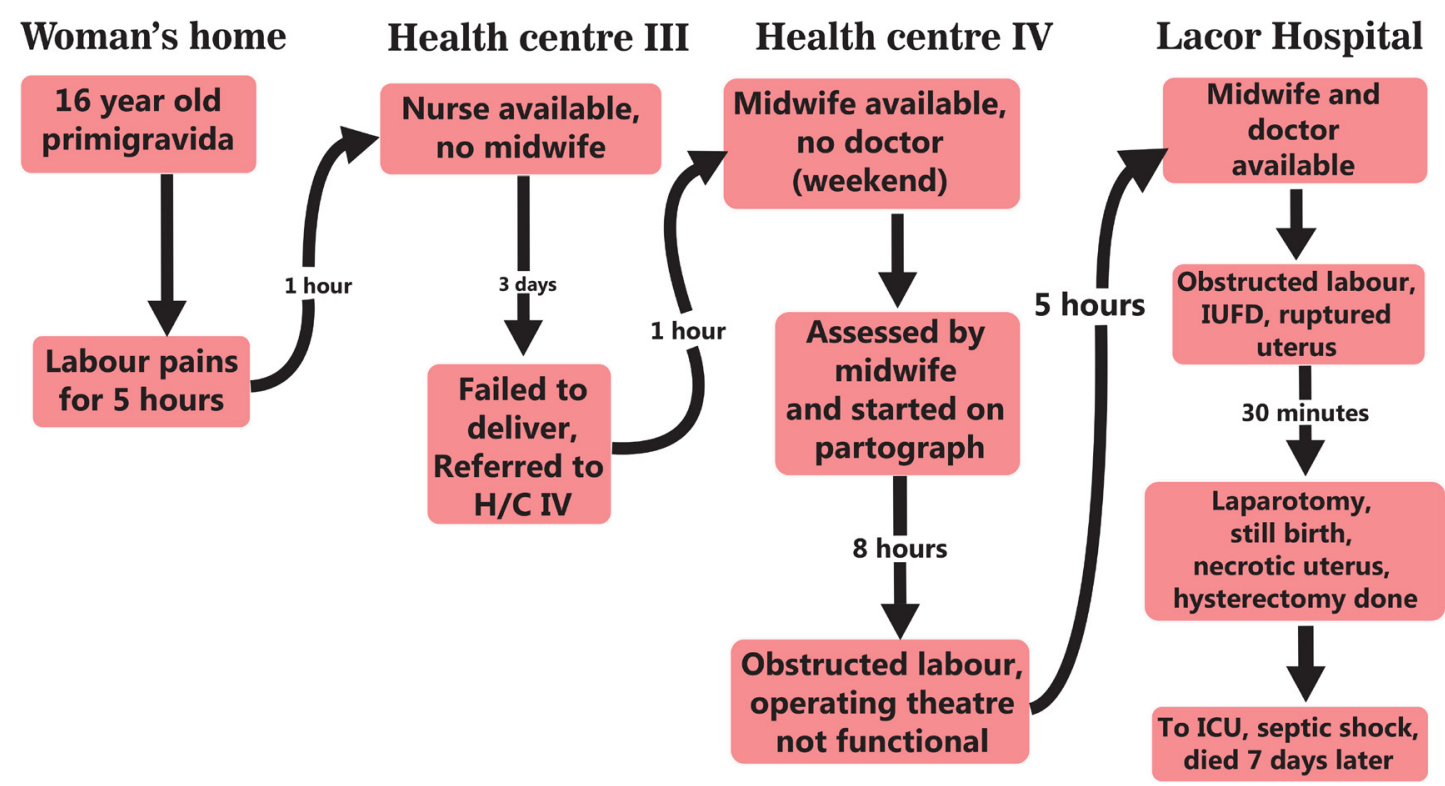

Figure 5 Delayed referral and operation. At H/C III, there was no midwife. The nurse who attended to the patient did not plot a partograph and kept her for 3 days. The patient requested a referral to $\mathrm{H} / \mathrm{C}$ IV, where she was found to have obstructed labour but there was no doctor to do a caesarean section. She was referred to Lacor Hospital with prolonged obstructed labour and a dead fetus. Emergency caesarean section was done, and she was taken to the ICU, but got sepsis and died (MD3). H/C, health centre; ICU, intensive care unit; MD, maternal death; IUFD, intrauterine fetal death.

I've not gone to many places to see how bad the roads are. But when it rains, the roads are impassable. We usually delay so much on the road and if it is a bad emergency, the mother can even lose the baby. (Ambulance driver, Lacor Hospital)

Many midwives were also concerned about delays in accessing ambulances. They attributed this to the centralised ambulance system. In the case of Lacor Hospital and its satellite $\mathrm{H} / \mathrm{Cs}$, the ambulance system is designed in such a way that they are stationed at the main hospital. In case of any emergency at the lower $\mathrm{H} / \mathrm{Cs}$, the ambulance is called from the main hospital, which is on average $70 \mathrm{~km}$ away. There is usually some delay owing to the bad roads in the remote areas where these $\mathrm{H} / \mathrm{Cs}$ are located.

For quality and quick response, we are not yet a hundred percent, because you can imagine a mother with cord prolapse is in Amuru, 75 kilometers away, then they discover, they have to call here [Lacor Hospital].

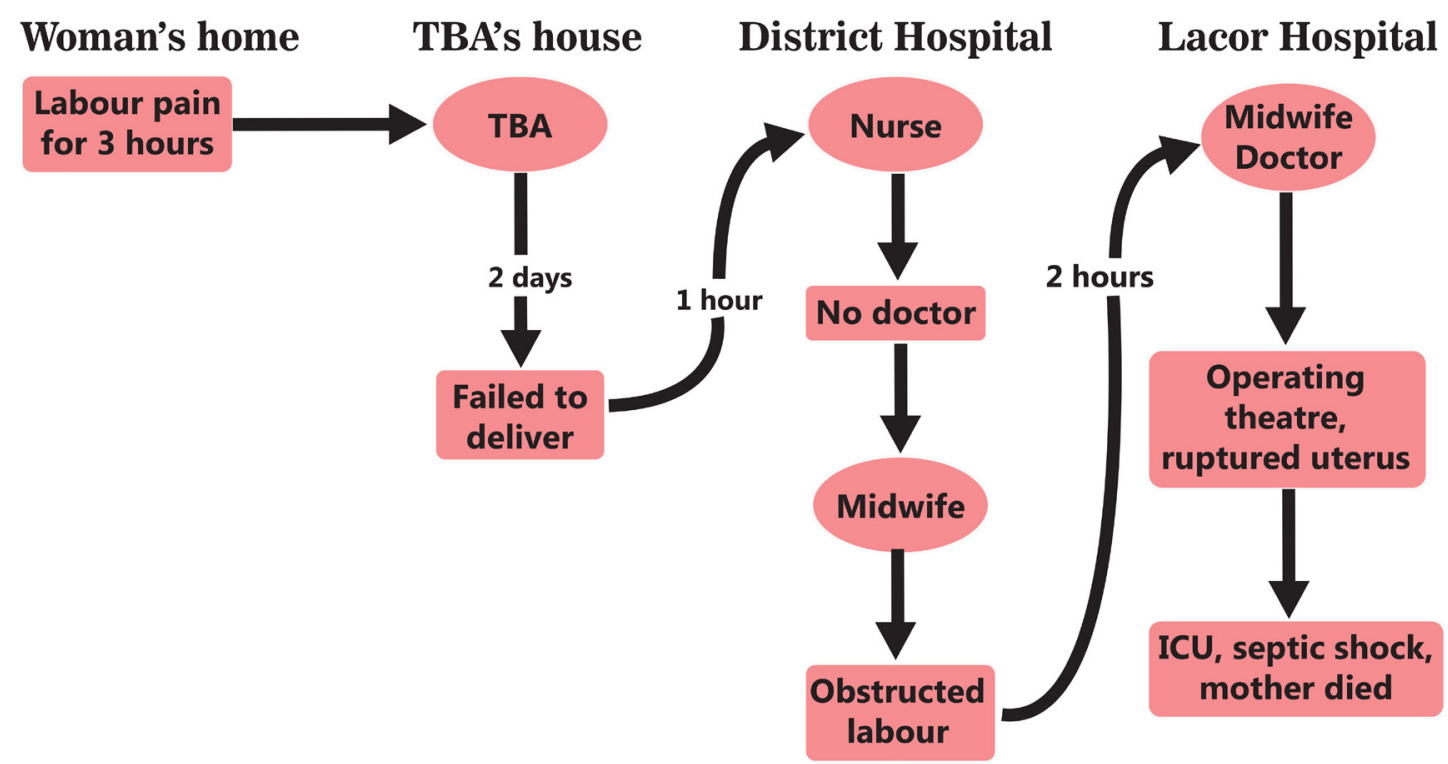

Figure 6 Non-functional facility and seeking care from the TBA. The mother had labour pain for 3 hours then went to TBA because the nearby H/C III had no midwife. The TBA kept her for 2 days until she failed to deliver. She was referred to the district hospital but the doctor was not available over the weekend, prompting referral to Lacor Hospital. She had a ruptured uterus and died of septic shock 4 days after the operation (MD4). H/C, health centre; ICU, intensive care unit; MD, maternal death; TBA, traditional birth attendant. 


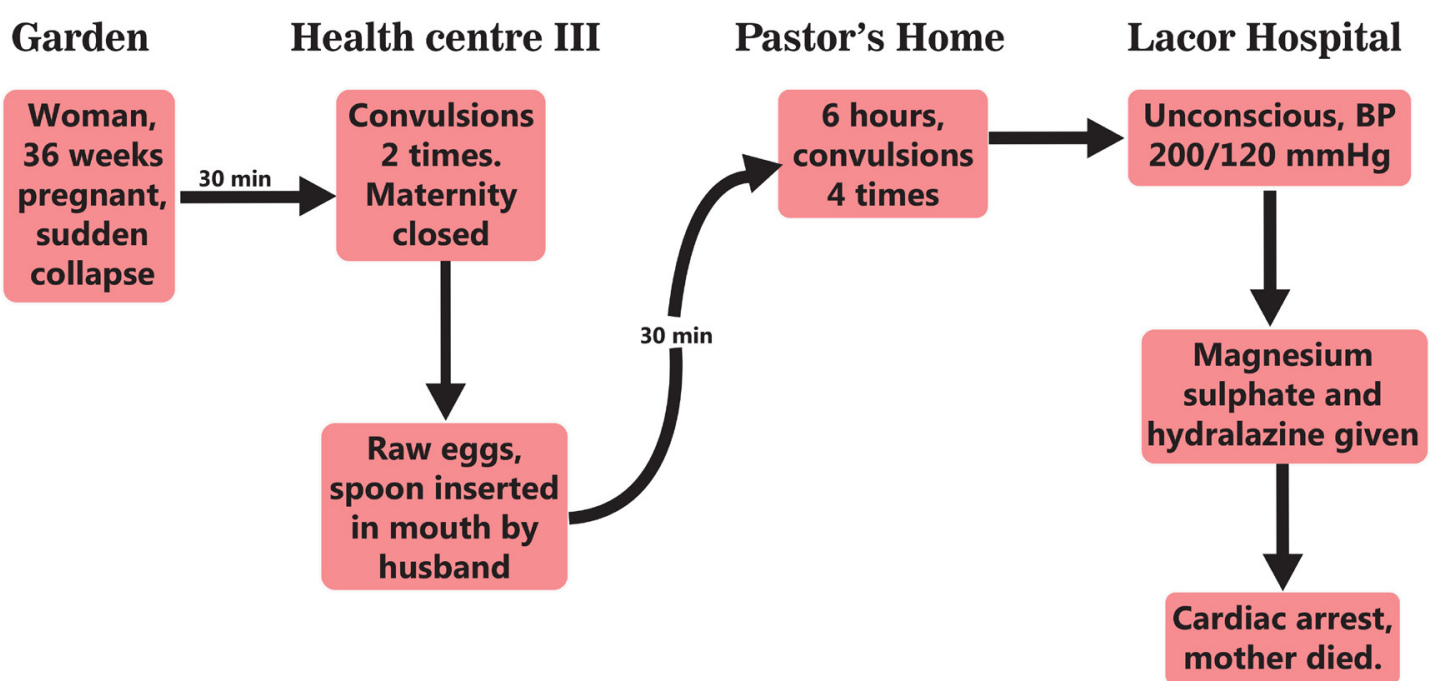

Figure 7 Non-functional BEmONC facility and seeking care from the religious leader. The woman suddenly collapsed from the garden. She was taken to H/C III and found the maternity unit closed because there was no midwife. After two episodes of convulsions, the husband gave her raw eggs and inserted a spoon in the mouth to stop her from biting the tongue. The motherin-law advised that the woman should be taken for prayers at the pastor's place since the condition could be related to evil spirits. She spent 6 hours with the pastor but continued to fit. When she deteriorated, the husband rushed her to Lacor Hospital, where her BP was found to be very high. She was given treatment but died after 30 min due to eclampsia. A perimortem operation was done and extracted a live baby (MD5). BEmONC, basic emergency obstetrics and newborn care; BP, blood pressure; $\mathrm{H} / \mathrm{C}$, health centre; $\mathrm{MD}$, maternal death.

So, there are delays sometimes. Some emergencies don't need any delay at all. (Midwife, Lacor Hospital)

The system for government facilities is not any different. The ambulances are stationed at the regional referral and district hospitals, but they have inadequate fuel most times.

For us, we have to call the district hospital for the ambulance. But you have to wait until the attendants get money for fuel. (Midwife from H/C III, who escorted a mother referred to Lira RRH)
It was reported that some patients are so poor and can spend the whole day trying to raise money for fuel. In some cases, they have to first go back home and sell land or animals.

\section{Zigzagging referrals}

In one of the pathways, we also noted a back-and-forth referral pattern. As illustrated in figure 9, each facility refers to the other in a zigzagging manner after failing to carry out a diagnostic test or an operation.

\section{Woman's home Health centre III Lacor Hospital}

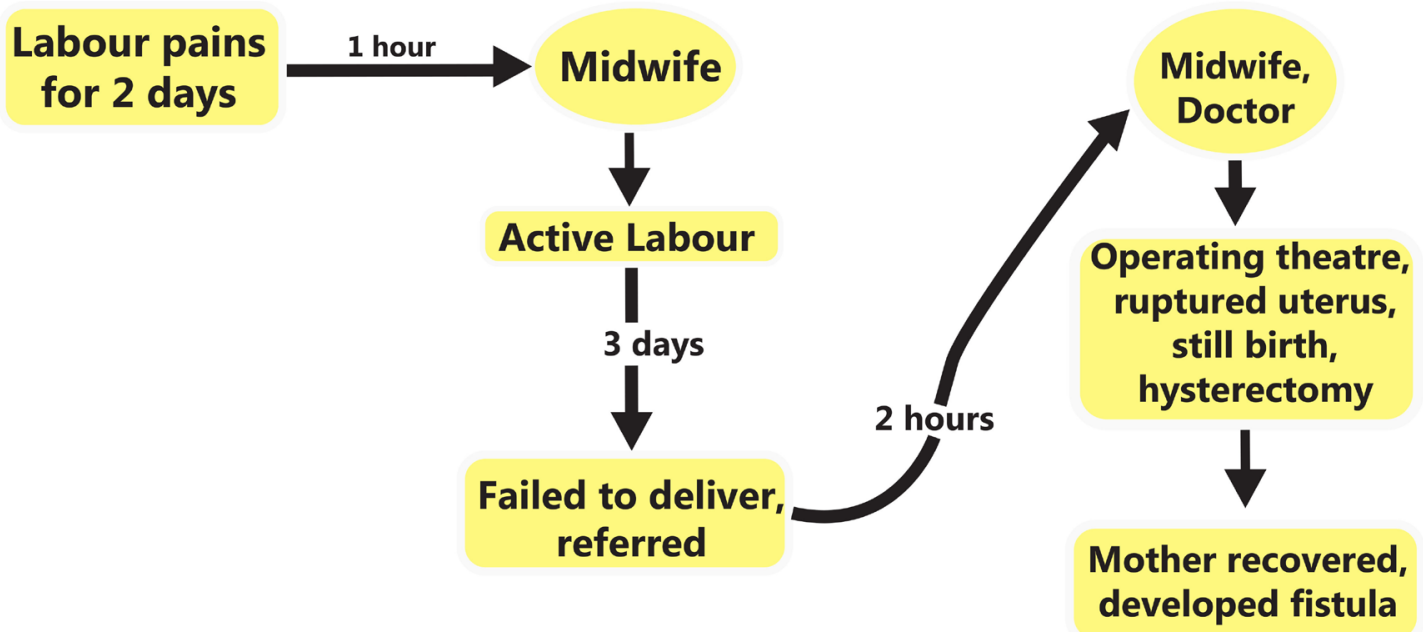

Figure 8 Skills of the health workers. The mother experienced labour pain for 2 days before going to the health centre. The midwife received her and gave her a bed without proper assessment. After 3 days of active contractions and exhaustion, the attendants requested a referral to Lacor Hospital. She arrived at Lacor Hospital with a ruptured uterus and was discharged with a vesicovaginal fistula (MNM2). MNM, maternal near-miss. 


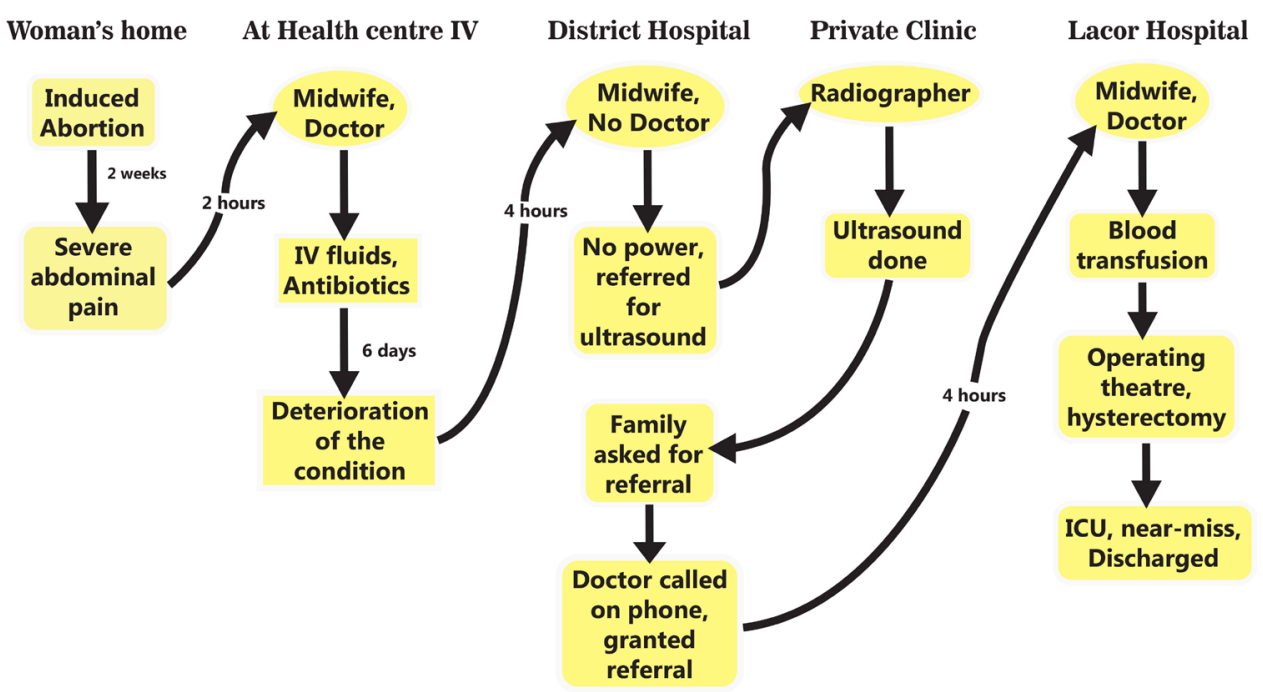

Figure 9 Back-and-forth referral due to lack of diagnostics. The mother had an unsafe abortion then went to H/C IV. The doctor reviewed and started her on antibiotics and intravenous (IV) fluids. She was referred to the district hospital for an abdominal ultrasound scan and complete blood count. Unfortunately, these investigations could not be done. She was again referred to a private medical centre for an ultrasound scan, which showed massive pus in the abdomen. The operation could not be done because there was no electricity. The family requested a referral to Lacor Hospital, where the operation was done. The uterus was removed and she was discharged alive after 5 days (MNM3). H/C, health centre; ICU, intensive care unit; MNM, maternal near-miss.

\section{DISCUSSION}

Although maternal deaths and near-misses have been largely studied with a major focus on biological causes of death, this study elucidated some intriguing reasons why mothers die even after making early contact with formal healthcare. In the pathways that we analysed, all the women took much longer than the common threshold while at the health facilities and developed complications. This is consistent with the definition of the duration of the third delay by Edson $e t a l^{24}$ The pathways to maternal mortality are highly influenced by a shortage of medicines and supplies necessary for the signal functions of EmONC. Typically, patients and attendants are 'shuffled around' to buy medicines and supplies, causing significant delays similar to findings from other LMICs. ${ }^{25}{ }^{26}$ Because most lower facilities lack medicines and supplies, some women had to trek across districts to access BEmONC services. This is contrary to the WHO recommendation of accessibility within $5 \mathrm{~km} .{ }^{27}$

As illustrated in the various pathways in this study, women who require CEmONC services often face significant challenges. Similar to most LMICs, lack of blood and blood products, gaps in coverage by doctors and anaesthetists, and power outages were major hindrances to accessing emergency operations. ${ }^{28}{ }^{29}$ Even in cases where emergency caesarean sections were done, the decision to operate took longer than the $30 \mathrm{~min}$ to 1 hour interval, as stipulated in some guidelines. ${ }^{30} 31$

The pathways described in this study show that women experience significant 'passive delays' due to limited practical capacity to identify and treat obstetric emergencies even in facilities with a fair stock of EmONC tracer drugs. Similarly, a study done in Kenya found that the availability of signal functions alone does not directly translate into a readiness to manage obstetric emergencies, but rather a clinical cascade that involves the ability to identify the emergency, treat it and monitor-modify therapy. ${ }^{32}$ Women who were first assessed by personnel with suboptimal midwifery skills, such as general nurses, nursing assistants and TBAs, were likely to die in most of the pathways. Some studies have found that these women receive wrong medicines, are not monitored and are often referred late. ${ }^{33} 34$

Evidence from LMICs shows that most BEmONC facilities refer between $60 \%$ and $80 \%$ of their patients to CEmONC facilities. ${ }^{35-37}$ A good referral system is therefore very important for good maternal and neonatal outcomes. ${ }^{38}{ }^{39}$ Similar to a study by Elmusharaf $e t a l,{ }^{40}$ our study elucidated four patterns of delays in the interfacility referrals: delay in deciding to refer, referral through multiple non-functioning CEmONC facilities, back-andforth referrals and bypassing CEmONC facilities that are deemed non-functional. The major point of delay in the referral system was the first point of care and often related to the capacity to identify complications promptly as highlighted in some studies. ${ }^{40} 41$

This study had some limitations that warrant cautious generalisation of the findings. We carried out all the interviews at the health facilities and this may pose response bias. However, we compared responses from respondents along similar pathways to eliminate gross response bias. Second, part of this study focused on the referral system, and the addition of two tertiary facilities in Lira without additional stepdown health centres might be a limitation to saturation of data and might not fully present the PHCC experience. Additionally, critical case sampling could 
be biased by researchers' selection interests. However, the researchers used independent MPDSR teams at the tertiary hospitals to identify cases based on the principles of analytical generalisation. Overall, the concept and understanding used in this study are transferable.

\section{CONCLUSION}

This study elucidated pathways typically characterised by delays at the health facilities. These pathways provide a novel framework to assess, track and improve the health facility's practical readiness to identify and treat obstetric emergencies. For example, health workers can work with mothers during the antenatal period to identify suitable blood donors and include this on the antenatal chart or engage with the Uganda Nurses and Midwives Council to address gaps in midwifery training, such as access to teaching hospitals and internship opportunities. The pathways also provide a qualitative, critical approach to clearly describe the third delay.

\section{Author affiliations}

${ }^{1}$ Obstetrics and Gynecology, Lira University, Lira, Uganda

${ }^{2}$ Obstetrics and Gynecology, St Mary's Hospital Lacor, Gulu, Uganda

${ }^{3}$ Public Health, St Mary's Hospital Lacor, Gulu, Uganda

${ }^{4}$ Public Health, Gulu University Faculty of Medicine, Gulu, Uganda

${ }^{5}$ Obstetrics and Gynecology, Torit State Hospital, Torit, South Sudan

${ }^{6}$ Maternal and Newborn Care, RHITES - North Acholi, Gulu, Uganda

${ }^{7}$ Obstetrics and Gynecology, Lacor Hospital, Gulu, Uganda

${ }^{8}$ Department of Obstetrics and Gynecology, Makerere University, Kampala, Uganda

${ }^{9}$ Obstetrics and Gynecology, Mulago National Referral Hospital, Kampala, Uganda

Twitter Gasthony Alobo @AGasthony and Josaphat Byamugisha @Byamugishajk10

Acknowledgements The authors particularly acknowledge Audrey-Jade ParisMigneault and Loubna Belaid for their guidance on CIT which has strongly informed the examination of the third delay presented in this current manuscript. The authors are also grateful to the patients and all the key informants for accepting to be interviewed. The authors thank Dr Oneka Francis and Okot Solomon Nono for editing images to meet the standards, and Professor Christina Zarowsky for proofreading the manuscript.

Contributors GA, AM and EO conceived the idea and wrote the design. VN and GA collected data. GA and EO carried out data analysis and writing of the manuscript. GA, PB and JB did the overall review and editing. All authors read and approved the final manuscript.

Funding This study only received support for ethical clearance from the Canada's International Development Research Centre (IDRC) through the MoCHeLaSS project.

Disclaimer The views expressed herein do not necessarily represent those of IDRC or its Board of Governors.

Competing interests None declared.

Patient consent for publication Not required.

Ethics approval This study was approved by the Lacor Hospital Institutional Research Ethics Committee (LHIREC) and the Uganda National Council for Science and Technology, within the Mother and Child Health Lacor and South Sudan (MoCHeLaSS) project.

Provenance and peer review Not commissioned; externally peer reviewed.

Data availability statement Data are available upon reasonable request from the corresponding author.

Supplemental material This content has been supplied by the author(s). It has not been vetted by BMJ Publishing Group Limited (BMJ) and may not have been peer-reviewed. Any opinions or recommendations discussed are solely those of the author(s) and are not endorsed by BMJ. BMJ disclaims all liability and responsibility arising from any reliance placed on the content. Where the content includes any translated material, BMJ does not warrant the accuracy and reliability of the translations (including but not limited to local regulations, clinical guidelines, terminology, drug names and drug dosages), and is not responsible for any error and/or omissions arising from translation and adaptation or otherwise.

Open access This is an open access article distributed in accordance with the Creative Commons Attribution Non Commercial (CC BY-NC 4.0) license, which permits others to distribute, remix, adapt, build upon this work non-commercially, and license their derivative works on different terms, provided the original work is properly cited, appropriate credit is given, any changes made indicated, and the use is non-commercial. See: http://creativecommons.org/licenses/by-nc/4.0/.

ORCID iDs

Gasthony Alobo http://orcid.org/0000-0002-4107-5047

Josaphat Byamugisha http://orcid.org/0000-0002-3438-9662

\section{REFERENCES}

1 WHO. Trends in maternal mortality 2000 to 2017: estimates by WHO, UNICEF, UNFPA, world bank group and the United Nations population division, 2019.

2 Alkema L, Chou D, Hogan D, et al. Global, regional, and national levels and trends in maternal mortality between 1990 and 2015, with scenario-based projections to 2030: a systematic analysis by the un maternal mortality estimation Inter-Agency group. Lancet 2016;387:462-74.

3 Murray CJL, King G, Lopez AD, et al. Armed conflict as a public health problem. BMJ 2002;324:346-9.

4 UDHS. Uganda demographic and health survey. Kampala Uganda: Uganda Bureau of Statistics, 2011.

5 Uganda Bureau of Statistics (UBOS) and ICF. Uganda demographic and health survey 2016: key indicators report. Rockville, Kampala, Uganda, and Maryland: UBOS, 2017.

6 Liebling $\mathrm{H}$, Barrett $\mathrm{H}$, Artz L. South Sudanese refugee survivors of sexual and gender-based violence and torture: health and justice service responses in northern Uganda. Int J Environ Res Public Health 2020;17:1685.

7 Chi PC, Bulage P, Urdal H, et al. Perceptions of the effects of armed conflict on maternal and reproductive health services and outcomes in Burundi and Northern Uganda: a qualitative study. BMC Int Health Hum Rights 2015;15:7.

8 Ngonzi J, Tornes YF, Mukasa PK, et al. Puerperal sepsis, the leading cause of maternal deaths at a tertiary university teaching hospital in Uganda. BMC Pregnancy Childbirth 2016;16:207.

9 Mukasa PK, Kabakyenga J, Senkungu JK, et al. Uterine rupture in a teaching hospital in Mbarara, Western Uganda, unmatched casecontrol study. Reprod Health 2013;10:29.

10 Zaba B, Whitworth J, Marston M, et al. HIV and mortality of mothers and children: evidence from cohort studies in Uganda, Tanzania, and Malawi. Epidemiology 2005;16:275-80.

11 Thaddeus S, Maine D. Too far to walk: maternal mortality in context. Soc Sci Med 1994;38:1091-110.

12 Goodman DM, Srofenyoh EK, Olufolabi AJ, et al. The third delay: understanding waiting time for obstetric referrals at a large regional hospital in Ghana. BMC Pregnancy Childbirth 2017;17:216.

13 Knight HE, Self A, Kennedy SH. Why are women dying when they reach hospital on time? A systematic review of the 'third delay'. PLoS One 2013;8:e63846.

14 Bayo P, Itua I, Francis SP, et al. Estimating the met need for emergency obstetric care $(\mathrm{EmOC})$ services in three payams of Torit County, South Sudan: a facility-based, retrospective cross-sectional study. BMJ Open 2018;8:e018739.

15 Holmer H, Oyerinde K, Meara JG, et al. The global met need for emergency obstetric care: a systematic review. BJOG 2015;122:183-9.

16 Admasu K, Haile-Mariam A, Bailey P. Indicators for availability, utilization, and quality of emergency obstetric care in Ethiopia, 2008. Int J Gynaecol Obstet 2011;115:101-5.

17 Ameh C, Msuya S, Hofman J, et al. Status of emergency obstetric care in six developing countries five years before the MDG targets for maternal and newborn health. PLoS One 2012;7:e49938.

18 Flanagan JC. The critical incident technique. Psychol Bull 1954;51:327-58.

19 Viergever RF. The critical incident technique: method or methodology? Qual Health Res 2019;29:1065-79.

20 Kemppainen JK. The critical incident technique and nursing care quality research. J Adv Nurs 2000;32:1264-71.

21 Cunningham U, De Brún A, McAuliffe E. Application of the critical incident technique in refining a realist initial programme theory. $B M C$ Med Res Methodol 2020;20:1-16. 
22 Etikan I, Musa SA, Alkassim RS. Comparison of convenience sampling and purposive sampling. Am J Theoret Appl Stat 2016;5:1-4.

23 Clarke V, Braun V, Hayfield N. Thematic analysis. qualitative psychology: a practical guide to research methods, 2015: 222-48.

24 Edson Wet al. Safe motherhood studies-timeliness of in-hospital care for treating obstetric emergencies: results from Benin, Ecuador, Jamaica, and Rwanda. Washington: United States Agency for International Development, 2006.

25 Mgawadere F, Unkels R, Kazembe A, et al. Factors associated with maternal mortality in Malawi: application of the three delays model. BMC Pregnancy Childbirth 2017;17:219.

26 Pacagnella RC, Cecatti JG, Parpinelli MA, et al. Delays in receiving obstetric care and poor maternal outcomes: results from a national multicentre cross-sectional study. BMC Pregnancy Childbirth 2014;14:159.

27 WHO and UNICEF. AMDD: monitoring emergency obstetric care: a handbook. Geneva: World Health Organization, 2016.

28 Ackers L, loannou E, Ackers-Johnson J. The impact of delays on maternal and neonatal outcomes in Ugandan public health facilities: the role of absenteeism. Health Policy Plan 2016;31:1152-61.

29 Urassa E, Massawe S, Lindmark G, et al. Operational factors affecting maternal mortality in Tanzania. Health Policy Plan 1997;12:50-7.

30 Excellence, N.I.f.C. Caesarean section-NICE clinical guideline 132. London, 2012. Available: https://www. nice. org. UK/guidance/cg132 [Accessed May 2016].

31 Practice ACoO. ACOG committee opinion no. 433: optimal goals for anesthesia care in obstetrics. Obstetric Anesthesia Digest 2010;30:78.
32 Cranmer JN, Dettinger J, Calkins K, et al. Beyond signal functions in global obstetric care: using a clinical cascade to measure emergency obstetric readiness. PLoS One 2018;13:e0184252.

33 Paul B, Mohapatra B, Kar K. Maternal deaths in a tertiary health care centre of Odisha: an in-depth study supplemented by verbal autopsy. Indian J Community Med 2011;36:213.

34 Pacagnella RC, Cecatti JG, Osis MJ, et al. The role of delays in severe maternal morbidity and mortality: expanding the conceptual framework. Reprod Health Matters 2012;20:155-63.

35 Jahn A, Kowalewski M, Kimatta SS. Obstetric care in southern Tanzania: does it reach those in need? Trop Med Int Health 1998;3:926-32.

36 Nkyekyer K. Peripartum referrals to Korle Bu teaching hospital, Ghana-a descriptive study. Trop Med Int Health 2000;5:811-7.

37 Bailey PE, Awoonor-Williams JK, Lebrun V, et al. Referral patterns through the lens of health facility readiness to manage obstetric complications: national facility-based results from Ghana. Reprod Health 2019;16:19.

38 Yego F, Stewart Williams J, Byles J, et al. A retrospective analysis of maternal and neonatal mortality at a teaching and referral hospital in Kenya. Reprod Health 2013;10:13.

39 Ramaswamy R, Iracane S, Srofenyoh E, et al. Transforming maternal and neonatal outcomes in tertiary hospitals in Ghana: an integrated approach for systems change. J Obstet Gynaecol Can 2015;37:905-14.

40 Elmusharaf K, Byrne E, AbuAgla A, et al. Patterns and determinants of pathways to reach comprehensive emergency obstetric and neonatal care (CEmONC) in South Sudan: qualitative diagrammatic pathway analysis. BMC Pregnancy Childbirth 2017;17:278.

41 Nuamah GB, Agyei-Baffour P, Akohene KM, et al. Incentives to yield to obstetric referrals in deprived areas of Amansie West district in the Ashanti region, Ghana. Int J Equity Health 2016;15:117. 